\title{
Experimentações fotográficas: 0 tempo como tema-dispositivo na pesquisa com imagens
}

\author{
Photographic experiments: time-device \\ in research with images
}

\begin{abstract}
Resumo: Este texto trata da discussão sobre o tempo e a fotografia através do trabalho de dois grupos de pesquisa que utilizam a fotografia como estratégia de pesquisa e produção de conhecimento. Neste texto, a problematização teórica faz referência aos conceitos de tempo em Bergson e de cronotopo em Bakhtin, para pensar os modos como tempo e espaço podem ser considerados através da fotografia. A fotografia é entendida como produção e como forma de habitar a duração no tempo, sua fugacidade e instantaneidade. A partir de duas narrativas fotográficas, que têm o tempo como tema-dispositivo para produção das imagens, as autoras discutem os efeitos nos modos contemporâneos do vi/ver.

Palavras-chave: Fotografia. Tempo. Pesquisar. Narrar.
\end{abstract}

\begin{abstract}
This paper deals with the quarrel on time and photography in the work of two academic groups that use photography as strategy of research and production of knowledge. In this paper, theoretical issues make reference to the concepts of time in Bergson and chronotope in Bakhtin, to think the ways as time and space can be thought through photography. Photograph is understood as production and as form to inhabit the duration in time, their fugacity and immediacy. From two photographic narratives, that have the time as subject-device for production of images, the authors argue the effect in contemporary ways of living. Keywords: Photography. Time. To research. Narrate.
\end{abstract}

SILVA; Paula Marques da; TITTONI, Jaqueline; AXT, Margarete. Experimentações fotográficas: o tempo como tema-dispositivo na pesquisa com imagens. Informática na Educação: teoria e prática, Porto Alegre, v. 16, n. 2, p. 203216, jul./dez. 2013.

\author{
Paula Marques da Silva \\ Jaqueline Tittoni \\ Margarete Axt \\ Universidade Federal do Rio Grande do Sul
}

\section{Sobre o fotografar como questão}

A produção deste texto/imagem é efeito do trabalho de dois grupos de pesquisa ${ }^{1}$, que vêm investindo em experimentações fotográficas como estratégia metodológica. $\mathrm{O}$ encontro entre estes grupos é marcado por indagações originadas das práticas de pesquisa

\footnotetext{
1 Estamos nos referindo, de um lado, ao grupo de pesquisa Trabalho, Ética e Estética, vinculado ao Programa de Pós Graduação em Psicologia Social e Institucional da Universidade Federal do Rio Grande do Sul - UFRGS, coordenado pela Professora Doutora Jaqueline Tittoni. Este grupo busca na pesquisa intervenção e na produção de fotografias, subsídios metodológicos para as pesquisas na área da Psicologia Social e Institucional. De outro, também compõe este texto o grupo de pesquisa vinculado ao Laboratório de Estudos em Linguagem, Interação e Cognição da mesma Universidade (LELIC/UFRGS), coordenado pela Professora Doutora Margarete Axt, comprometido com Contextos Interativos e Virtuais com Tecnologias para Aprendizagem e Simulação (Civitas), os quais têm se constituído em dispositivo de in(ter)venção para pensar e atualizar modos de conhecer, de conviver e de expressar, numa perspectiva ético-política e estética, no âmbito da pesquisa em educação.
} 
e relacionadas à trajetória investigativa vinculada à fotografia. Fotografar o tempo em sua fluidez e inscrevê-lo em alguma linha de visibilidade possível constitui uma provocação ao incansável desejo de fixá-lo, organizá-lo e circunscrevê-lo, traduzindo-o por intermédio de imagens instituintes de narrativas sobre a vida e o viver.

Tempo e fotografia estão, desde as primeiras experimentações fotográficas, ligados por múltiplos modos de inscrição em superfícies sensíveis à definição de contornos de luz. Para além da inscrição da luz no plano das superfícies e do espaço, Batchen (2004) aponta que o surgimento da fotografia está relacionada, em particular, à possibilidade de registrar e fixar o tempo nas imagens. As imagens fotográficas, assim, provocam os domínios do tempo como captura de um instante preciso e sensível e como possibilidade de duração, definindo a fotografia, como sugere Geoff (2008), como um instante contínuo. Mas também o provocam enquanto intervalo entre instantes, "ali onde se dá o corte" - o click do fotógrafo; um entre-tempos que, "ao alojar as emoções, as afecções", aloja, também "uma multiplicidade de sentidos" (AXT; MARTINS, 2008).

Para Batchen (2004), é necessário pensar que o surgimento da fotografia implicou em processos técnicos - químicos, físicos, mecânicos, entre outros - mas também no desejo de dominar o tempo, fazendo-o durar no exercício de torná-lo visível por meio de alguma tradução. O desejo de fotografar, para o autor, foi tão importante quanto os recursos técnicos que o tornam possível.

Este texto convida a "ver" o tempo nas marcas que lhe dão passagem através dos recursos fotográficos e, assim, problematizar sua potência nos modos de viver, conhecer e pesquisar. Trata-se, portanto, de um convite para uma aventura nas experimentações do fotografar, onde o sensível e o impossível nos provocam a ser diferentes.

\section{Sobre tempo e fotografia}

A história da produção fotográfica nos convoca a pensar nas múltiplas maneiras como o tempo vem sendo experimentado nos modos de viver. Lissosvky (2003) aponta que nas primeiras produções imagéticas de Niépce, a partir de 1829 e também de Daguerre, a partir de 1840, o tempo se configurava como um elemento problemático no campo do registro. Isso se dava, sobretudo, em função das longas horas de exposição da "chapa" nos processos de fotossensiblização e também pela impossibilidade de registrar corpos em movimento. Por volta de 1870, a fotografia tornou-se instantânea em virtude, principalmente, da utilização de substâncias mais sensíveis e de obturadores mais rápidos. A tecnologia do instantâneo, segundo o autor, marcou uma época em que os fotógrafos buscavam dominar o tempo, acessando velocidades maiores e minimizando o "tempo" de exposição no ato fotográfico.

Nessa mesma linha de pensamento, Sanz (2011) aponta que, na modernidade, as noções de fotografia e de instante passaram a se configurar de maneira recíproca e simultânea. As tecnologias visuais modernas estavam atreladas ao processo de fragmentação e de microdinamização do tempo. Do mesmo modo, o próprio conceito de instante transitou culturalmente no percurso de produção das tecnologias da imagem, sobretudo da fotografia. A autora julga importante destacar que a incessante busca pela captura de acontecimentos atuais e efêmeros no campo da instantanização fotográfica não é efeito apenas 
de uma "corrida técnica", mas de múltiplos vetores constituídos nos planos da ciência, da estética e da política.

Sanz argumenta ainda que a fotografia esteve amplamente entrelaçada aos valores indexibilidade e legibilidade temporal. No plano da ciência, por exemplo, sobretudo as cronofotografias de Jassen, Muybridge, Jules Marey e Albert Londe ${ }^{2}$, são instauradoras de efetiva aderência entre o instante e a fotografia, demarcando um sincronismo entre o movimento do relógio e a produção de imagens instantâneas. Nesse contexto, o tempo métrico, homogêneo e espacializado encontra na produção fotográfica grande legitimidade. Em outro texto Sanz (2008) sugere que a fotografia configurou-se circunscrita ao instantâneo, mas fortemente ligada à cronologia e à captura espacial, encontrando-se, em relação ao tempo, fora da duração. Imagem fotográfica como paralisia e contração radical do movimento, demarcando "fotografias no tempo e não tempos na fotografia" (p.4).

Seguindo essa mesma linha de reflexão, Wunder (2006) argumenta que a racionalidade científica moderna dá ênfase a um modo de visão regularizado, formalizado e pautado, principalmente, em procedimentos de avaliação e controle que produzem um olhar geometrizado que classifica, avalia, corrige e se distancia das sensibilidades. Tal discussão ganha relevância e se desdobra no próprio processo de como a produção de imagens opera nos modos de olhar e na produção das formas de visibilidade e de visibilização da vida e do viver (TITTONI, 2011).

\footnotetext{
2 De acordo com Lissovsky (2003), por volta de 1870 fotógrafos como Muybridge e Jules Marey dedicaram-se à produção de cronofotografias. Na cronofotografia diversas câmeras eram disparadas com intuito de capturar seqüencialmente o movimento de corpos humanos e de animais. Esse modo de produzir imagem colocava a produção fotográfica vinculada ao tempo como movimento.
}

Ao trazermos nuances da história da fotografia, não buscamos evidenciar os processos evolutivos que perpassam as tecnologias da imagem: a história aqui é margeada através da transitoriedade dos acontecimentos, dos movimentos que seguem fluxos diversos, das tensões permanentes no jogo de forças constituído por saberes e poderes. Trata-se de um movimento que, tanto pode encontrar regularidades, quanto seguir rupturas nos contextos a serem percorridos. Nesse sentido, assume uma função de assinalar o fotografar e a fotografia na medida em que carregam marcas instituídas e modelares que operam nos modos de olhar, determinando o sentir e o viver.

Neste texto, ao instaurar o tempo como tema-dispositivo (TITTONI, 2011), colocamo-nos no movimento fotográfico e de escrita, em relação de tensão com essas lógicas de fixação do tempo e de enquadramento do espaço. A pergunta que insiste diz então sobre o tensionamento entre instante e duração na fotografia e no fotografar.

A noção de tema-dispositivo está ligada à noção de dispositivo em Deleuze (1990) que, a partir de Michel Foucault, nos mostra o dispositivo como um arranjo composto por linhas multíplices e heterogêneas, as quais se articulam em formas plurais e se ressignificam constantemente de maneira simultânea. Dentre as diferentes linhas que compõem este "novelo multilinear" estão pelo menos duas, as linhas de estratificação ou de sedimentação (as linhas molares, duras) que normatizam; e as linhas de ruptura ou fissura (frágeis linhas de criação) que, ao mesmo tempo, no dispositivo, marcam "a sua capacidade de se transformar, ou desde logo se fissurar em proveito de um dispositivo futuro" (p. 6).

Linhas de sedimentação, reguladoras e inflexíveis, instituem as formas duras do viver e 
indicam os padrões culturais ("ser mulher é..."; "ser homem é..."). Já as linhas de fissura ou de ruptura deslocam e tensionam os fluxos vedados para abrir passagem à invenção de outros modos de existência. Deste modo, fazem irromper forças em confronto no curso do vi/ ver: ver no infinitivo, fluxo em puro devir; vi, enquanto memória virtualizada que tanto pode molarizar quanto molecularizar, na dependência das forças segundo as quais a memória é provocada/convocada; vi/ver, enquanto composição de modos de existir em movimento num presente, desde sempre invadido e determinado por um passado passando, tanto quanto em permanente escoamento em direção a um porvir se insinuando.

No campo da pesquisa com imagem, o uso da noção de dispositivo em interface com o tema "tempo na fotografia", nos lança no plano dos regimes de visibilidades e dizibilidades que indicam os modos de vi/ver nos movimentos de uma determinada época. Mapear linhas desta rede de conexões implica instalar-se no dispositivo e percorrer fios da experimentação fotográfica que compõe este pesquisar sempre em processo. Pista potente para tensionar lógicas que instituem a fixidez do tempo e o esquadrinhamento do espaço no ato fotográfico, produzindo também outras potências nas trajetórias investigativas. É quando, para nós, se instaura então um campo de experimentação afetiva e de análise dos fluxos do sentir/sentido com forte acento na criação. Uso das imagens compondo, a um só tempo, o traçar nos planos ético-político dos encontros com a alteridade no tensionamento eu-para-mim-eu-para-o-outro; e estético das provisórias produções (polifônicas e polissêmicas) do vi/ver.

Em outras palavras, ao trajetarmos (AXT, 2011) o tema-dispositivo "tempo na fotogra- fia", hibridizamos este texto nas tramas de uma experimentação fotográfica. Fotografar "o tempo" tornou-se de uma só vez desafio e possibilidade de borrar as fronteiras rígidas entre pesquisa, arte e sensibilidade. Exercício fotográfico que acolhe o tempo como elemento paradoxal nos modos de pesquisar com imagens.

Nessa composição, produzimos duas narrativas fotográficas que se interpelam mutuamente, fazendo-se tapeçaria na urdidura conjunta de imagens, olhares, palavras e conceitos. A primeira narrativa é intitulada "Na superfície da pele: imagemnarrada no tempo", agenciando imagem verbal-fotográfica em seus sentidos polissêmicos, produzindo no tempo - pois narração é sempre no tempo dobrada-desdobrada -, uma hibridação luz-palavra-linhas-superfícies.

A segunda narrativa "tempos fugidios: detalhes, instantes e instantâneos", provoca tempo e espaço, dando visibilidade às marcas do tempo nas inscrições de espaços urbanos. O recurso fotográfico do tom "sépia" mostra o jogo das imagens onde as tonalidades se produzem nos jogos sensíveis entre uma certa homogeneização da cor e as múltiplas possibilidades de diferenciação provocadas pela incidência da luz, do foco ou de suas combinações. Este recurso busca intensificar a sensação da ação do tempo e sua visibilidade nas imagens produzidas, assinalando-o na produção das imagens, e ainda na sua concepção, dessa maneira permitindo pensar também a intencionalidade do fotógrafo e dos modos de fotografar.

As narrativas estão compostas de imagem e de escrita e foram realizadas como um exercício fotográfico das autoras na produção do campos de análise das pesquisas em desenvolvimento. Este exercício foi proposto tendo 
o tempo como tema-dispositivo e sua experimentação em imagens, como a proposta do trabalho. Desta forma, estão entrelaçadas as escritas e as imagens produzidas como diários de campo e como experimentações do pesquisar. Estas narrativas indicam que há um campo de relações de força entre o visível e o enunciável e não uma relação de conformidade, de correspondência ou de redutibilidade. Esta perspectiva, de irredutibilidade entre 0 dizer/escrever/ver, está embasada nas concepções foucaultiana e deleuziana e sugere mais fortemente uma relação agonistica, podendo provocar diferentes combinações e modos de dizer/escrever/ver.

Para os autores, os enunciados não são as unidades lingüísticas significantes, palavras, frases, proposições ou atos de linguagem, mas uma função que cruza as diversas unidades e, de igual maneira, as visibilidades, que não se confundem com os elementos visuais. Assim, como é preciso "rachar" e abrir as palavras, as frases e as proposições, também é preciso "rachar" as coisas e a vista, para extrair, delas, as possibilidades e os enunciados de cada estrato (DELEUZE, 1988).

As reflexões produzidas nas narrativas originam-se deste jogo entre a escrita e a imagem, ou, da mesma forma, entre as dizibilidades e visibilidades. Ambas buscam o tempo como tema-dispositivo e o constroem de formas diferenciadas. Na primeira, a concepção da imagem do tempo na fotografias passou pelas imagens da pele, do tempo que se faz corpo, sensível, trabalho. Na segunda, o tempo aparece como traços, resquícios e marcas que tratam as palavras como imagens. Desta forma, a proposta de realizar imagens tendo o tempo como tema-dispositivo construiu os jogos de visibilidade-dizibilidade que compõem nossas reflexões.

\section{Na superfície da pele: imagem- narrada no tempo}
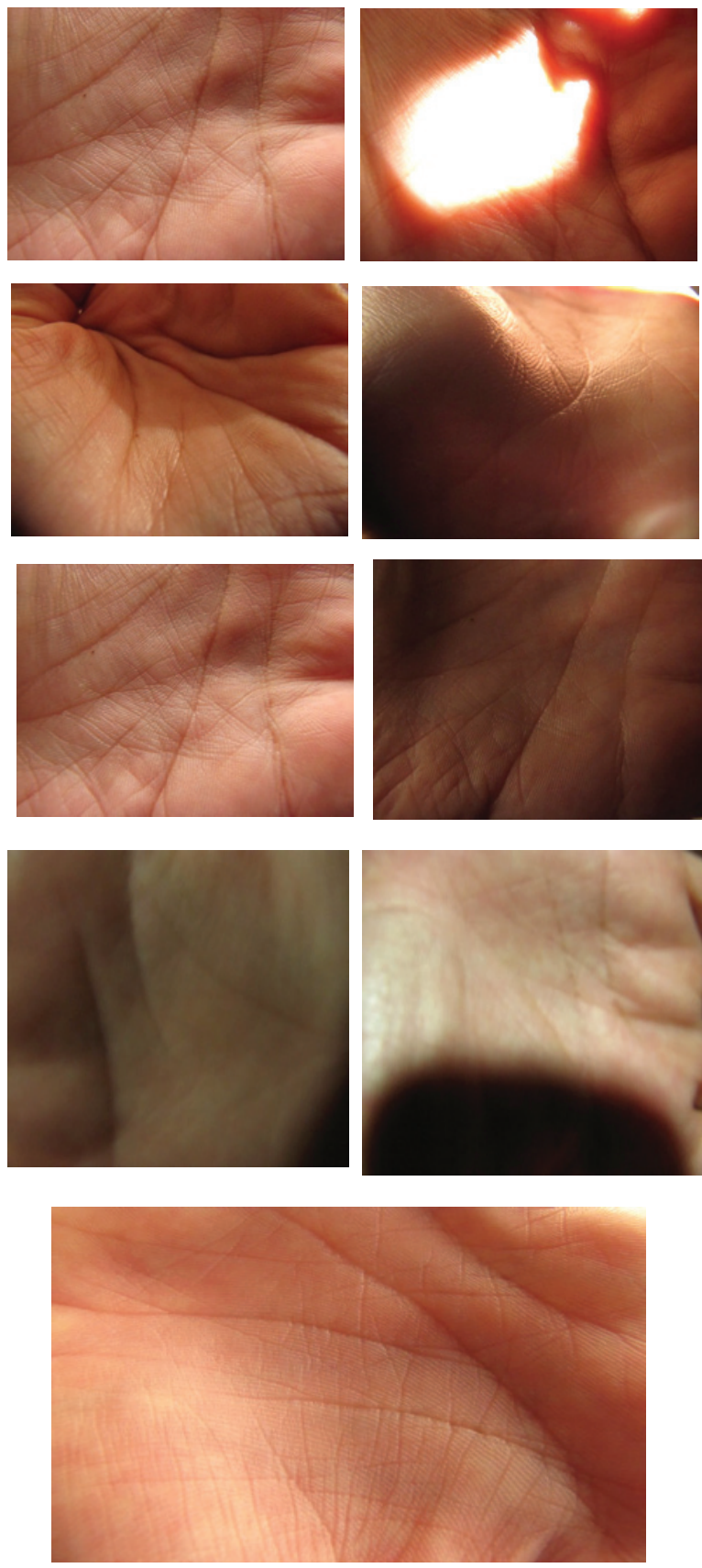
Habitar uma experimentação fotográfica percorrendo as linhas de força do tempo como tema-dispositivo foi a provocação que abriu possibilidade para este narrarfotografar. Exercício que, inicialmente, parecia fácil. Bastava uma câmera fotográfica e o percurso do olhar à espreita daquilo que é tão cotidiano e onipresente, o tempo. No entanto, os dias, os minutos e segundos se passavam e algo parecia "silenciar" o olhar na cadência de uma temporalidade fatigada e mecânica. Tal qual areia movediça, o tempo se fez armadilha. Os ponteiros dos relógios pareciam ditar e conter os modos de ver. Era preciso deslocar os pontos de vista que se mantinham tão ancorados em uma cronologia linear e deixar-se arrastar pelo movimento vivo da vida. Nesse fluxo de hesitações, a geografia da pele de mulheres que trabalham em vários lugares da cidade fez tessitura com os trajetos do olhar-fazer-sentir fotográfico. Encontrei Magnólia à beira do fogão, mexendo o feijão em uma grande panela. Perguntei a ela se podia fotografar as linhas de sua mão. Com uma gargalhada que apimenta o caldo denso, ela responde: "a linha da vida que está marcada na minha mão não pode ser essa que todos dizem ser". Trabalho há 28 anos na cozinha e a minha mão tem a marca das queimaduras de panela, dos calos feitos pelos cabos da colher de pau e das preocupações com um tempo que está sempre por chegar. De tempo eu sei muito e muito pouco. De "olho" sei que a carne no fogo já se deu pronta, que o arroz passou do ponto, que as bolhas de água na chaleira fazem reclamar a patroa que não gosta do chimarrão fervendo. Mas, às vezes sinto que a vida pode virar o caldo, ficar perigosa e sem rumo". Um outro encontro se faz em um agitado salão de beleza.Carmem e Cecília estão frente a frente com as mãos entrelaçadas. Em uma harmoniosa dança feita de ferramentas e toques, Carmem, manicure e contadora de histórias, faz das mãos de Cecília palco de arte e precisão. Unhas vermelhas vão se desenhando no esboço de gestos sutis e de cumplicidade. Após fotografar as mãos destas mulheres e mostrar-Ihes o que foi fotografado, Carmem se surpreende ao olhar as imagens produzidas: "há cinco anos 'faço a tua mão' e nunca tinha olhado para os traços que acabo de ver. Para mim, a mão de uma mulher está toda nas unhas". "Acho que também nunca olhei direito para as tuas mãos", responde Cecília diante das observações feitas pela manicure. Cecília continua a conversa dizendo que "se as linhas da palma da mão definem o tempo e o jeito de uma vida, eu, ao menos, dou uma colorida na vida de muita gente".

Acostumada com os disparos fotográficos, Eugênia, diz que eu poderia fotografar, tranquilamente, as suas obras. Mulher de delicados movimentos, faz do barro forma e expressão em uma artesania que prende o olhar dos transeuntes que passeiam pelo Parque da Redenção/POA. Perguntei a ela se poderia fotografar as linhas de sua mão. Ela abre a mão dizendo que as linhas foram se apagando e tomando outros desenhos de tanto mexer com barro e fazer dele gente. (M. -S, 20/03/2012, notas - cenas, imagens do diário de campo).

No movimento imagéticonarrado dessa primeira narrativa, "Na superfície da pele: imagemnarrada no tempo", o percurso do nosso olhar-falar fez morada movente no encontro com a geografia da pele das mãos de mulheres trabalhadoras. Mulheres que laboram 0 cotidiano e texturizam a vida nas amarras de um tempo automatizado, mas também, que podem se abrir a um vi/ver inventivo levadas nos fios de uma imagemnarrada. Desafios do escrever e exercício foto-sensível que ganham densidade nas cenas fotográfico-verbais que a narrativa enuncia, rompendo com o instituído que confina o ato fotográfico-verbal no campo do registro e da instantanização espacializada. Trata-se de trajetar imagensnarradas e deixar-se afetar por hesitações - escolhas no plano da criação e da invenção.

Trajetar fotográfico que faz elos com Deleuze (1992) quando menciona a frase "O mais 
profundo é a pele" de Paul Valéry (VALÉRY apud DELEUZE, 1992 p. 109). A partir deste fragmento poético, Deleuze afirma a possibilidade de pensarmos a filosofia como a arte das superfícies. Superfícies que remetem à constituição de um plano de inscrição enquanto resistência ao que não está oculto. O autor sugere ainda que "Se você não constituir uma superfície de inscrição o não oculto permanecerá não visível (p. 109)".

Deleuze nos convoca a pensar em uma experimentação fotográfica que não está voltada para o oculto, àquilo que poderia estar por detrás da imagem. Não há, nesta perspectiva, o que desvelar; tampouco há uma essência escondida no plano da superfície desta imagem/ pele: superfícies resistem escrachando o não-oculto. Seguindo esta linha de reflexão, afirmamos que, no campo da pesquisa com imagens, o nosso interesse recai sobre os regimes de visibilidade e invisibilidade que, inscritos nos planos de superfície, constituem cronotopos (BAKHTIN, 1997) para modos de vi/ver. Nesse processo, a visibilidade não se restringe ao objeto, tampouco reside no sujeito, "mas no reconhecimento de que cada visível guarda também uma dobra invisível que é preciso percorrer a cada instante e a cada momento" (NOVAES, 2000, p. 27).

Nesse processo, o encontro com as trabaIhadoras, o produzir as fotografias e o compor o mapa/pele/imagemnarrada são linhas que se agenciam e se sustentam num mesmo campo problemático: "o tempo do fotografarnarrar" instaura, não tanto uma geometria temporal abstrata do espaço, antes uma geografia da pele, linhas inscritas em uma superfície: na duração do tempo, um lugar concreto para o sentido, vale dizer um cronotopo para vi/ver imagensnarradas.

Axt (2011) define assim o conceito de sentido - "Inscrito no passado, o sentido produz-se concretamente no presente, no trajeto-imagem de um corpo: este presente, este corpo - tempo-lugar do sentido - sentido emergido-ativado por trajetos-imagens, constituindo um agir e um dizer singulares, histórias narrativas inéditas" (p. 100) -, enquanto pensa a imagem como lugar de inscrição do tempo-movimento concernido à duração bergsoniana, um cronotopo na inspiração bakhtiniana:

tempo em escoamento e lugar concreto entrelaçam-se em um'cronotopo', sustentando o lugar do sentido, sentido em movimento, movimento em ação produzindo trajetos, trajetos em processo de enredamento com emoções-sensações produzindo imagens, imagens abrindo as portas à criação (AXT, 2011, p. 100).

Com a noção de 'cronotopo' o fotografarnarrar torna-se, num mesmo movimento, "lugar e tempo" em se fazendo no fluxo do devir. $^{3}$ Este movimento cronotopico, que se faz no curso vivo da experiência, parece que nos lança, quando se trata do pesquisar, a fluxos incessantes, da ordem do imprevisível. Não se planejou a fotografia, embora fotografar estivesse na mira do olhar; não se planejou a narração embora dizer-falar estivesse na ponta da língua. Tais argumentações ganham força no âmbito do percurso desta narrativa visual indicando um trajeto investigativo que se faz no próprio trajetar. Trata-se de movimento que não se reduz a um espaço parametrizado ou a um tempo pontual-instantâneo, mas que se configura como lugar-tempo no próprio ato de

\footnotetext{
${ }^{3}$ Remetendo a Deleuze, Axt (2010) aponta o devir como aquele processo do tempo em sua duração que se faz a si no fluxo, em meio à contingência da vida, que não pretende alcançar determinada forma, uma identidade, mas que vai ao encontro de uma zona que, em lhe sendo vizinha ou próxima (o próximo passo), todavia the é indiscernível, desconhecido destino (vazio em aberto). Não se trata de futuro, ressalta Deleuze, devir e futuro se distinguem, pois que futuro planeja-se, esquadrinha-se.
} 
percorrer uma geografia que se inscreve nessa superfície à medida que emerge.

Em diálogo com Bergson (2006), podemos pensar que, neste trajetar-narrar-fotográfico, "o tempo é móvel e imedível" (p. 5). O autor ressalta que medir o tempo trata-se de uma convenção formulada pela força de sua imobilização. Dessa maneira, ao tomarmos o tempo seguindo um ordenamento métrico acabamos por excluir a mobilidade no percurso de algo móvel por natureza: é quando se perde o cronotopo para o sentido!

Elaborações como as de Bergson nos deixam no rastro de uma pista fundamental para pensarmos o trajetar no plano do narrar fotográfico. Estamos referindo ao tempo como duração. Ao trazer a ideia da duração, Bergson (2006) tensiona os processos da vida enquanto pensados a partir de um tempo cronologicamente linear e enquanto submetidos a uma lógica do espaço. Nesse entendimento, a "previsibilidade é uma abstração" (p. 104).

Para o autor, o movimento da vida implica indivisibilidade, duração e continuidade, adquirindo "formas inesperadas". A duração, nessa concepção, não corresponde a algo linear, mas é do fluxo da vida em que o tempo age tornando-se "veículo de criação" (p. 107). Trata-se, como sugerem Marques-Silva et al. (2011), de um constante exercício de desacomodação dos atos mais conhecidos e mecanizados, dando consistência a formas inesperadas que, em geral, deixam de ser enunciadas por serem capturadas pelo modo instituído, normatizado, automatizado de vivermos.

Seguindo essa linha de pensamento Lissovsky (2003) sugere pensar o instante de forma imanente, e não como uma exterioridade que se abate sobre um contínuo. $O$ instante fotográfico remete a uma deriva, onde nos misturamos e nos dissolvemos nele. Esta concepção segundo o autor "procura reconhecer o devir do instante como uma modulação no âmbito da duração" (p. 4).

Ao instalarmo-nos na duração, o pesquisar passa a nos provocar para adentrar no território do sensível, território existencial provocando rachaduras no já dito-visto e suas obviedades; e alçando o tempo em campo problemático no próprio movimento em curso, ali onde os processos fluem. A produção da narrativa imagemnarrada se manifesta, desse modo, em um "processo-durando, no entre-tempos [...] uma diminuta hesitação produzindo escolhas, ao emergir entre instantes, mas na continuidade da duração, na sucessividade do tempo em relação a si próprio" (AXT, 2010, p. 10). O entre-tempos, situado entre dois instantes, não é propriamente tempo, dirão Deleuze e Guattari (1997, p. 203), é antes de tudo devir, acontecimento. Para nós, acontecimento que dura em potência intensivo-afectiva na imagemnarrada, inscrita e atualizada como luz e letra na superfície do suporte, e por isso durando: mas não por se encontrar fixada num tempo pontual ou imobilizada-enquadrada num espaço; e sim, por fazer retornar, no novo presente, a emoção, a intensidade do acontecimento passado-durando, assim abrindo "aos processos de virtualização do atual, deixando-se impregnar de séries de sentidos em fluxo, estetizando-se e, logo, tornando-se expressão estética" (AXT, 2010, p. 11). Em nosso entender, o entre-tempos inscreve-se como cronotopo para "a produção de sentidos, de escolhas, de criação... [...], transbordando percepções e afecções vividas/sentidas" (AXT; MARTINS, 2008). 


\section{Tempos fugidios: detalhes, ins- tantes e instantâneos}

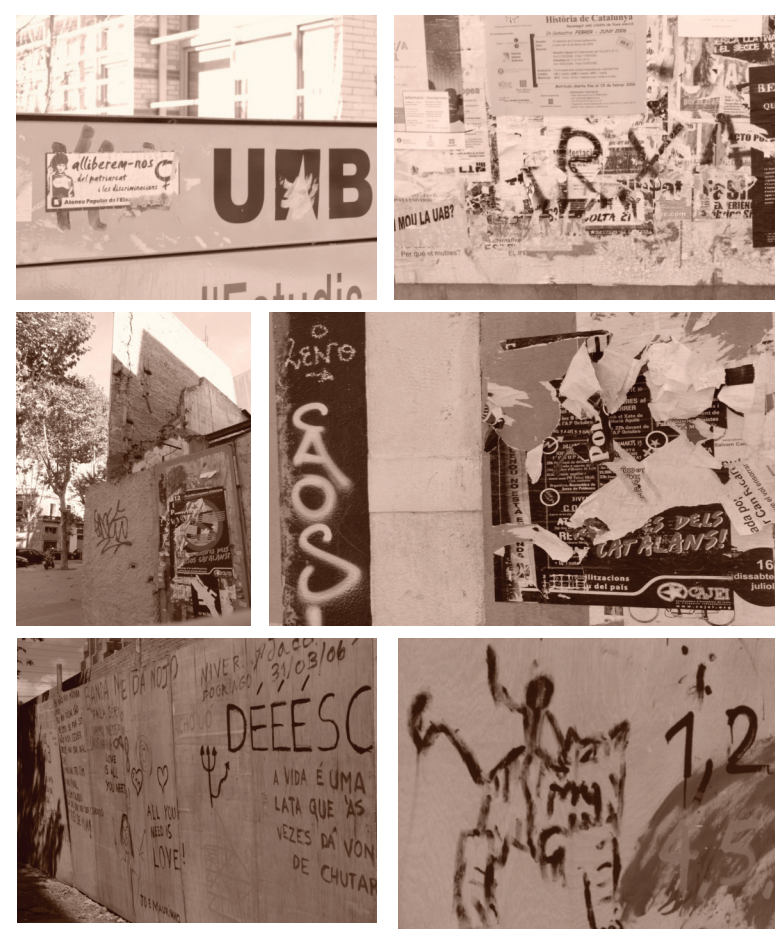

Andar pela cidade à procura do tempo foi o exercício proposto neste fotografar. Andar pela cidade, na cidade e nos seus detalhes, em caminhos que permitem "ver" outras visibilidades, percorrer outros trajetos e assim reconstruir a cidade com outras referências ou referentes. Na simplicidade do caminhar, a complexidade do olhar provoca e produz outras cidades, compondo territórios existenciais: na prática, outras cidades-territórios para viver o provisório, o passageiro e não a cidade onde vivo ou suponho viver, estando mais fortemente fixado, permanente... Na prática, uma cidade-território em que me é possível ser fotógrafa, pois os tempos que definem as interações possíveis podem ser menos velozes, definidos e intencionais. Pode-se habitar, de certa maneira, a instabilidade do instantâneo, do fugidio, do que "escapa" dos rumos pré-definidos que orientam, na maioria das vezes, nossos percursos pelas cidades, onde vivemos as supostas permanências. Sim, outra cidade e, assim, a possibilidade de também ser outra e provocar o devir fotógrafa que sempre se enuncia...

O detalhe, já nestas fotos antigas produzidas em 2006... Sim, "antigas" é uma provocação... A visibilidade do tempo está nos detalhes que persistem nas imagens, apesar das condições desfavoráveis. O tempo marcado como o detalhe que persiste. Mosaico de informações, imagens, textos, os murais de uma universidade transbordam de vida: alguém precisa de um quarto para viver, alguém possui um quarto desabitado em casa. Alguns vendem seu trabalho e sua experiência profissional e outros precisam de alguém que traduza alguma coisa para que possa acessar outra língua, outras passagens...

Luta-se muito nos detalhes: ali, em quase dez centímetros quadrados exige-se a liberdade da Catalunha, doma-se um tigre a cada dia e a liberdade encontra pequenas passagens, onde protege-se dos arroubos neoliberais e se faz brotar nos detalhes a lembrar que é nos atos micropolíticos, até mesmo invisíveis para quem passa em alta velocidade, focado em seus objetivos, que a liberdade se faz durar...

O instante duradouro que se faz visível no tablado que esconde a biblioteca: certa feita, mais ou menos em 2006, o Instituto de Psicologia da Ufrgs fez uma reforma no seu prédio e construiu a nova biblioteca. $O$ tapume que a escondia - depois de uma noite de muito pensar dos estudantes que sempre se encontravam pontualmente às $8 \mathrm{~h} 30 \mathrm{~min}$ e fizeram "parar" o tempo no "psico oito e meia" que existe até nossos dias - apareceu marcado pelas suas idéias, desejos e temores. Como tapume provisório, marcou e passou. Tapume que se mostrou, naquele instantâneo, como um avesso do conhecimento que se armazena e cataloga, pulsando de afeto e de vida... Em seu avesso, a biblioteca e seus volumes nos mostravam cenas da vida e duas análises. Onde foi parar aquele tapume marcado? $(T, j$. Arquivos - imagens de diário de campo em 2006) 
Na narrativa dois, "Tempos fugidios: detalhes, instantes e instantâneos", a discussão sobre o instante e o instantâneo provoca simultaneamente as noções de duração e de instantaneidade ao mostrar o tempo em dois sentidos, pelo menos: nos efeitos de transformação das colagens e pichações sobrepostas e nos modos como as temporalidades marcam os espaços urbanos, indicando diferentes modos de viver a urbe e suas possibilidades. O tempo na cidade aparece como traços de uma subjetivação fugaz que, ao passar, marca os trajetos e define percursos no tempo e no espaço. São como rastros e pegadas de alguém que se faz ver pelos efeitos de sua caminhada. Estas marcas do tempo na cotidianidade da urbe evocam o tempo nos modos como pode mostrar-se nas diferentes composições da imagem.

A noção de instante decisivo, em Cartier-Bresson (1971) indica que, nas imagens, a duração do tempo se faz perceber na mesma intensidade de sua instantaneidade e precariedade, na mesma direção das proposições bergsonianas e deleuzo-guattarianianas. Para Cartier-Bresson, a fotografia "fixa, para sempre, o instante preciso e transitório" (p. 21, 1971), mas cabe aos fotógrafos "capturar o movimento fugidio e todas as interrelações que se acham em movimento" (p. 21, 1971). Este ato de "fixar", no entanto, se desfaz a cada olhar que reconstrói a imagem no plano dos sentidos, retornando o que entendemos por acontecimento (no entre-tempos). O cronotopo do sentido, enquanto tempo-espaço em movimento, pode tornar visível, no plano apreciativo, a experimentação de um instante que será sempre outro em outras experimentações.

A fotografia, na visão do fotógrafo, está na relação possível entre o instante e a cena, entre o tempo e o espaço, sintetizados no arranjo composicional das múltiplas linhas que a compõe.
O instante e o instantâneo provocam a noção de duração, trazendo para a espacialidade da imagem fotográfica, o tempo traduzido no instante. Instante que, ao mesmo tempo, pode ser "fixado", mas que escapa ao ser recomposto pelos diferentes olhares a que é sujeito.

Alves e Contani (2008) sugerem que o instante decisivo, pensado a partir da noção de signo estético nas formulações piercenianas, é um quali-signo, ou seja, é um ícone ou uma qualidade, que é um signo. Desta forma, necessita existir no mundo, mas é "um sentimento, uma consciência que pode ser incluída em um instante de tempo, consciência passiva, sem reconhecimento, sem análise" (p. 136). Para os autores, as qualidades do sentimento estarão, assim, corporificadas. Por ser um signo estético, a fotografia estará marcada pela espontaneidade e pela originalidade, expressas na sua composição como um modo de vi/ver, diríamos nós. Na estética de Cartier-Bresson , o instante compõe a imagem e ordena seus elementos, rearranjando os detalhes e dando voz aos diferentes elementos aí presentes.

Assim, a produção fotográfica produz-se no tempo, na lógica da duração e da intensidade do instante, que ordena sua composição.

Para Alves e Contani (2008, p. 140), o instante decisivo está no campo do indeterminado, dependendo da intuição do fotógrafo diante da fugacidade do momento. Segundo os autores, ele é estético "porque explora os momentos fugazes que estão no mundo, para conectar-se a tudo e a todos emanando sentimentos"

O narrarfotografar o tempo ao produzir-se como cronotopo e como instante decisivo, busca habitar a duração na intensidade dos sentimentos, dos afetos e das emoções, potencializando a invenção de diferentes modos de vi/ ver.

\section{2}




\section{Algumas poucas considerações: fotografarnarrar a imagemnarrada}

As narrativas de imagens "Na superfície da pele: imagemnarrada no tempo" e "Tempos fugidios: detalhes, instantes e instantâneos", mostraram/falaram a intensificação da experiência do tempo como duração. Nosso desafio se firma em pensar estas estratégias de fotografar e narrar imagens como uma linha de acolhimento das variações da experiência na duração, instaurando movimentos no território do tempo inventivo. Desafio que ganha vida e expressão na poesia de Manoel de Barros (2001) ao escrever "Fotografei o sobre. Foi difícil fotografar o sobre" (p. 12). Com esta escrita fotográfica o poeta abre passagens para pensarmos na complexidade do ato de fotografar. Trata-se de arte poética fazendo-nos adentrar o território existencial das sensibilidades, rompendo com o já dado e com as obviedades.

As narrativas imagéticas produzidas neste narrarfotografa, ou fotografarnarrar, e seus desdobramentos apreciativos querem provocar a fotografia e sua narrativa como estratégia de produção de conhecimento acadêmico, bem como de apreciação ético-estética. Ao provocar, agonisticamente nos colocam no plano das experimentações e, então, do acolhimento das incertezas como parte do trabalhar, do trajetar e do pesquisar, abrindo passagens para o inventar. Assim, estas considerações se propõem incitar a insistir no trajetar inventivo, pois mesmo trajetando na duração, fronteiras se impõem, limitando, bloqueando linhas criativas a por-se em movimento, fazendo desanimar.

Neste texto, tratamos da fotografia narrada no tempo, aproveitando para definir alguns marcadores históricos que operaram sua função de dispositivo; também trouxemos duas narrativas fotográficas, dando a ver temas do vi/ver que nos pungem. Em continuidade, pensamos apreciativamente através das noções de cronotopo, duração, entre-tempos e instante decisivo. Estes movimentos, como referido logo de início, foram realizados na trilha do desejo (mais do que impossível, intolerável) de vi/ver o tempo nas marcas que Ihe dão passagem através dos recursos fotográficos, assim abrindo à sua potência nos modos de fotografarnarrar.

O texto tratou-se, portanto, de um convite para experimentar o fotografarnarrar, onde o sensível e o impossível vem nos incitando a desviar o tempo-espaço cronológico-parametrizado em favor de uma estética das intensidades afectivas sustentada no virtual das possibilidades de sentido.

Para pensar na sua (do sentido) potência de produção de fluxos, inscrevendo novas/outras linhas de visibilidade/dizibilidade em nossa atividade de pesquisar, perguntamos, inicialmente, como operar com a fotografia na imprevisibilidade, no movimento e na fugacidade dos instantes, de modo a potencializar a invenção e deslocá-la das lógicas de enquadramento e representação, onde, muitas vezes, se mostra aprisionada, em especial quando se trata de produções acadêmicas.

Algumas pistas apontaram para o fotografarnarrar enquanto composição ético-estética dos sentidos em movimento: estes, em habitando a duração em seu devir intensivo, tendem a contaminar os próprios processos analíticos em relação ao ato do produzir imagensnarradas, transfigurando-as em apreciações de caráter estético.

Como imagemnarrada técnica, o fotografarnarrar implica aparelhos e sujeitos, saberes e verdades; como experimentação ético-estética, implica emoções e afetos marcados pelos 
modos de vi/ver. Como imagemnarrada que se produz no desejo moderno de "fixar" o tempo, acaba contraditoriamente por habitar a fugacidade do instante, instalando-se no intervalo do entre-tempos. Como imagemnarrada que se produz no desejo de "retratar a realidade", acaba paradoxalmente mostrando a diversidade dos olhares, dos pontos de vista, dos instantes fugidios. Como estratégia de pesquisa, mostra que o vivo transborda das verdades pré-definidas e instala-se nas artes da invenção e, assim, pesquisar é uma experimentação de vi/ver que pode, sempre, potencializar o virtual em sua mesma potência, para fazer retornar o acontecimento, o diferir em sua diferença.

As narrativas "Tempos fugidios: detalhes, instantes e instantâneos" e "Na superfície da pele: imagemnarrada no tempo", trazem para cena uma prática de pesquisa em que o pes- quisador faz escolhas, puxa fios, faz conexões com eles, entrando em seu próprio arranjo composicional e participando dos efeitos do seu movimento inventivo. Esses fios constituídos e constitutivos, fazendo elos entre sentidos em produção, entre imagens, falas e audições, podem ser compreendidos como linhas de apreciação ético-estética (e de análise científica) que implicam a função de dispositivo que as estratégias metodológicas adquirem. No encontro do fotografarnarrar com os tempos da duração, a imagemnarrada pode operar como dispositivo para potencializar linhas de criação, sustentando o jogo entre (in)visibilidades e (in)dizibilidades enquanto cronotopo para a passagem das intensidades, no complexo diálogo entre tecnologia, arte, filosofia e ciência, contribuindo para instaurar a multiplicidade $\mathrm{n} /$ dos modos de pesquisar e subjetivar.

\section{Referências}

ALVES, Rafhael Freire; CONTANI, Miguel Luiz. O instante decisivo: uma estética anárquica para o olhar contemporâneo. Discursos Fotográficos. Londrina, v. 4, n. 4, p. 127-44, 2008.

AXT, Margarete. Trajetos imagens: por uma cronotopia dos sentidos na pesquisa. In: ZANELLA, Andréa Vieira; TITTONI, Jaqueline (Orgs.). Imagens no pesquisar: experimentações. Porto Alegre: Ed Dom Quixote, 2011.

Encontro Clio entre gerações: por uma escuta dos sentidos na maturidade velhice. 2010 (mimeo).

MARTINS, Marcio. Coexistir na diferença: de quando a formação em serviço pensa modos de habitar a sala de aula. In: TRINDADE, Iole Maria Favieiro (Org.). Múltiplas Alfabetizações e Alfabetismos. Porto Alegre: Editora UFRGS, 2008.

BAKHTIN, Mikhail. A estética da criação verbal. São Paulo: Martins Fontes, 1997. 
BARROS, Manuel de. O Fotógrafo. Ensaios Fotográficos. Rio de Janeiro: Record, 2001.

BATCHEN, Geoffrey. Arder en deseos: La concepcion de la fotografía. Barcelona: Gustavo Gili, 2004; Editora Barcelona: Gedisa, 1990, p. 155-61.

BERGSON, Henri. O pensamento e o movente. São Paulo: Martins Fontes, 2006.

CARTIER-BRESSON, Henri. O momento decisivo. In: BACELLAR, Mário Clark (Org.). Fotografia e Jornalismo. São Paulo, Escola de Comunicações e Artes (USP), 1971, p. 19-26.

DELEUZE, Gilles. Que és un dispositivo? In: FOUCAULT, Michel. Barcelona: Gedisa, 1990, p. 155161. Tradução de Wanderson flor do nascimento. Disponível em: www.escolanomade.org. Acesso em: 20/03/2012.

DELEUZE, Gilles; GUATTARI, Felix. O que é a filosofia? Rio de Janeiro: Editora 34, 1997.

Conversações. Tradução de Peter Pál Pelbart. Rio de Janeiro: Editora 34, 1992.

Foucault. São Paulo: Brasiliense, 1988.

GEOFF, Dyer. O isntante contínuo. São Paulo: Companhia das Letras, 2008.

LISSOVSKY, Mauricio. O Tempo e a originalidade da Fotografia moderna. DOCTORS, Márcio. (Org.) Tempo dos Tempos. Rio de Janeiro, 2003, p. 142-165.

MARQUES-SILVA, Paula; LAZZAROTO; Gislei; AXT, Margarete. Liberdade para aprender: "Estou livre. Hoje não tem trabalho em casa e não estou de castigo". XVI ENCONTRO NACIONAL DE PSICOLOGIA SOCIAL DA ABRAPSO. Anais eletrônicos... [recurso eletrônico]. Recife, 16, 2011.

NOVAES, Adauto. Não se vê com os olhos. In: BAVCAR, Evgen. O ponto zero da fotografia. Rio de Janeiro: Very Special Arts, 2000, p. 25-36.

SANZ, Claudia. Quando o tempo fugiu do instantâneo. Revista Studium. 2011. Disponível em: http:// www.studium.iar.unicamp.br/32/4.html. Acesso em: 11 abr. 2012.

Resenha de LISSOVSKY, Mauricio. A máquina de esperar: origem e estética da fotografia moderna. Rio de Janeiro: Maud X, 2008. Disponível em: http://www.paratyemfoco.com/blog/wp-content/uploads/2009/08/O-jogos-dos-fot\%C3\%B3grafos-modernos.pdf. Acesso em: 12 abr. 2012.

TITTONI, Jaqueline. O fotografar, a poética e os detalhes. In: ZANELLA, Andréa Vieira; TITTONI, Jaque- 
line. Imagens no pesquisar: experimentações. Porto Alegre: Ed Dom Quixote, 2011.

WUNDER, Alik. Fotografias como exercícios de olhar. In: 29a Reunião Anual da Associação de Pós-Graduação e Pesquisa em Educação (ANPED), 2006, Caxambu, MG. Disponível em http://www. anped.org.br/reunioes/29ra/trabalhos/trabalho/GT16-2359--Int.pdf Acesso em: 10 abr. 2012.

Submetido para avaliação em 15 de maio de 2012.

Aprovado para publicação em 02 de maio de 2013.

Paula Marques da Silva: Mestre em Psicologia Social e Institucional (PPGPSI/UFRGS); doutoranda em Educação no Programa de Pós-Graduação em Educação pela Universidade Federal do Rio Grande do Sul (PPGEDU/UFRGS); Bolsista Capes - Porto Alegre-RS - Brasil.

E-mail: paulilinha1976@yahoo.com.br

Jaqueline Tittoni: Doutora em Sociologia pela Universidade Federal do Rio Grande do Sul com pós- doutorado em Psicologia Social na Universidade Autônoma de Barcelona; professora adjunta da Universidade Federal do Rio Grande do Sul com atuação no Instituto de Psicologia e no Programa de Pós-Graduação de Psicologia Social e Institucional (UFRGS) - Porto Alegre-RS - Brasil.

E-mail: jaquemin@terra.com.br

Margarete Axt: Doutora em Linguística e Letras pela Pontifícia Universidade Católica do Rio Grande do Sul; professora Titular da Universidade Federal do Rio Grande do Sul, com atuação nos Programas de Pós-Graduação em Educação (PPGEDU/UFRGS) e em Informática na Educação (PPGIE/UFRGS). Coordena o Laboratório de Estudos em Linguagem, Interação e Cognição (LELIC), Bolsista de Produtividade em Pesquisa do CNPq - Porto Alegre-RS - Brasil. E-mail: maaxt03@gmail.com 